\title{
Levels of Nitrous Oxide Exposure during Use of a New Application System in Healthy Male Volunteers
}

Regina Patricia Schukro M.D. and Sibylle Pramhas M.D.1, Asami Naka M.D.1, Andreas Gleiss Ph.D.2, Christoph Schukro3, Hans-Georg Kress M.D., Ph.D. FFPMCAI1, Sabine Sator-Katzenschlager M.D.1

1Departement of Special Anesthesia and Pain Therapy, Medical University Vienna

2 Center for Medical Statistics, Informatics, and Intelligent Systems, Medical University of Vienna

3Departement of Internal Medicine, Division of Cardiology, Medical University Vienna

\section{Introduction}

A mixture of $50 \%$ nitrous oxide and $50 \%$ oxygen is widely used during short surgical procedures . However, some very severe side effects are related to long term exposure to nitrous oxide (e.g. in intensive care or hospital personnel) [1]. In Austria, the professional use of anesthetic gases is controlled via the MAK-value (maximum working place concentration), which consists of a short-term limitation (400ppm) and a long-term limitation (100ppm) [2] .

\section{Patients and Methods}

Methods: The application system (Excidio ${ }^{\mathrm{TM}}$, Linde Group) is designed to eliminate nitrous oxide from the room air efficiently, by means of a scavenging system. The aim of the study was to investigate whether the Austrian work place concentrations for nitrous oxide are exceeded. 36 male healthy volunteers were included in this study. Volunteers were requested to inhale nitrous oxide via face mask for 15 minutes. Nitrous oxide concentration was analyzed during and after inhalation at 2 measurement points in $15 \mathrm{~cm}$ and $1 \mathrm{~m}$ distance from the nose of the volunteer by a continuous gas analyzer.

\section{Results}

The current study showed that nitrous oxide levels using the new application system partially exceeded the Austrian short-term limitation of $400 \mathrm{ppm}$ (29.4\% of all volunteers) in $15 \mathrm{~cm}$ distance to the face mask, which is the working area of medical personnel. $43.3 \%$ of all volunteers exceeded the long-term limitation of $100 \mathrm{ppm}$ at $15 \mathrm{~cm}$ distance from the face mask. On average, the long-term limit was exceeded for 6 minutes and by a median of 77 ppm (IQR 26-171).

\section{Conclusion}

As there is no clear evidence what the toxic levels of nitrous oxide in clinical practice are, the clinical significance of these findings is open to interpretation. Further studies are needed to test this system in patients under real life working conditions.

\section{References}

1.European Industrial Gas Association (EIGA) 2008: Review of Toxicological Data on Nitrous Oxide MGC 153/08 2.AUVA: Sicherer Umgang mit Narkosegasen- Sicherheitsinformation der allgemeinen Unfallsversicherungsanstal. M135-0606, Erste Auflage 2003

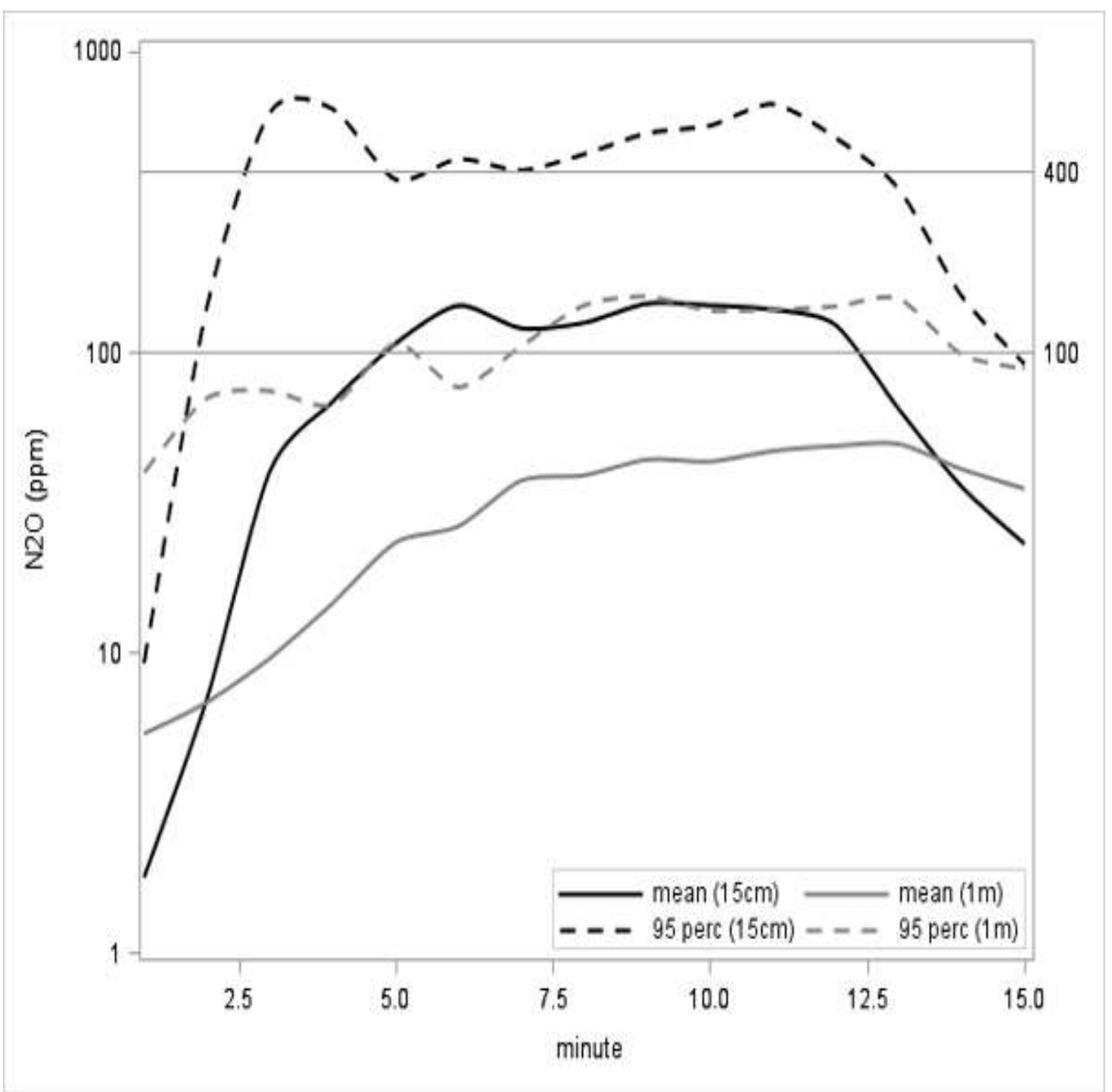

Figure 1: Average concentration of nitrous oxide

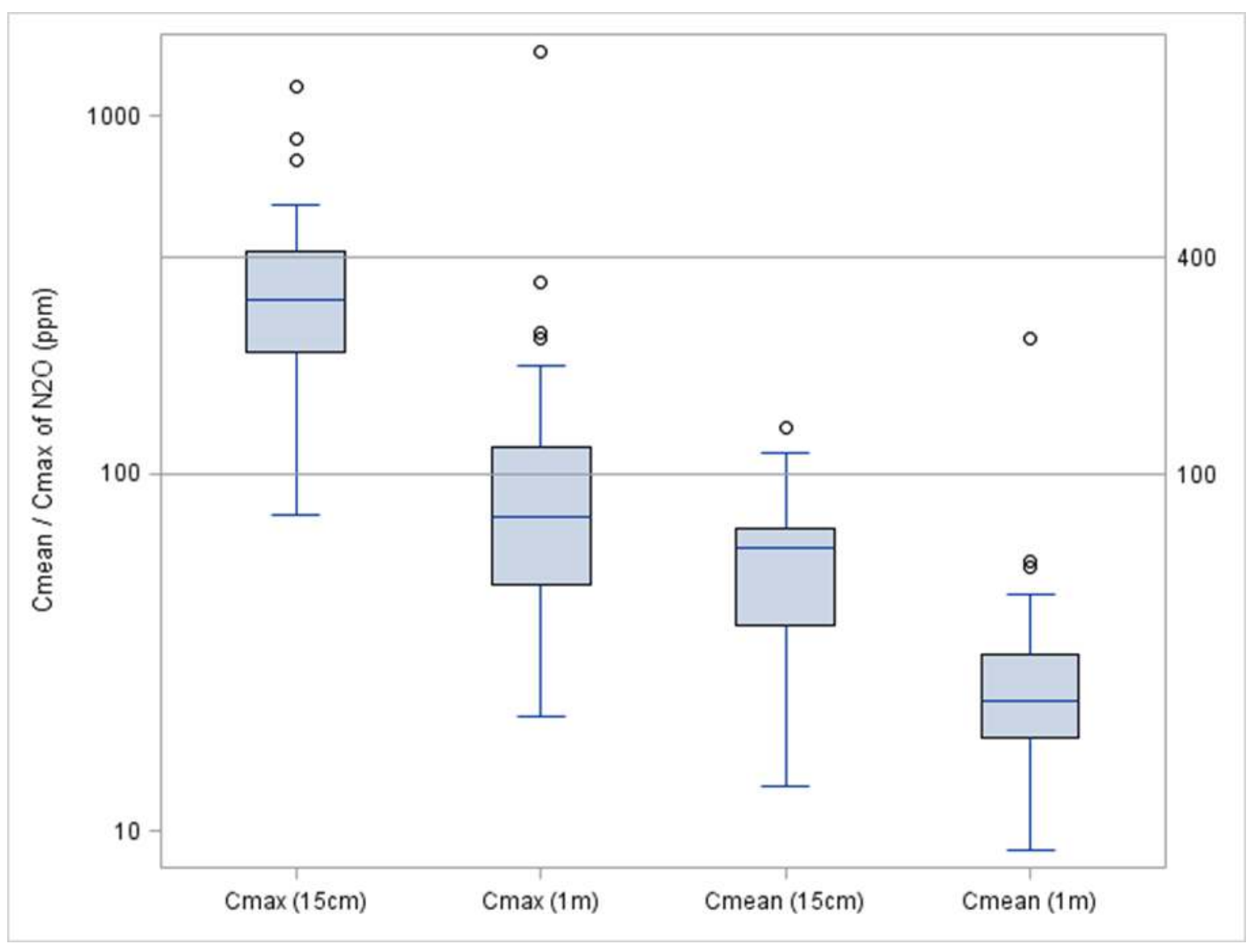

Figure 2: Maximum and Mean Concentration of Nitrous Oxide 